\title{
New plasmid calibrators for geminivirus-resistant (EMB-PV051-1 event) common bean (Phaseolus vulgaris L.) quantitation using simplex and duplex qPCR
}

\author{
Gustavo Luiz Venturelli ${ }^{\mathrm{a}}$, Kelly Justin da Silva ${ }^{\mathrm{a}}$, Diana Treml ${ }^{\mathrm{a}}$, Paola Beatriz Navas ${ }^{\mathrm{a}}$, \\ Maryella Osório Vargas ${ }^{\mathrm{a}}$, Joana Laura Bischoff ${ }^{\mathrm{a}}$, Josias Correa de Faria ${ }^{\mathrm{b}}$, \\ Ana Carolina Maisonnave Arisi ${ }^{a \text {,* }}$ \\ ${ }^{a}$ Food Science and Technology Department, Agrarian Science Center, Federal University of Santa Catarina, Florianópolis, SC, Brazil \\ ${ }^{\mathrm{b}}$ Embrapa Arroz e Feijão, Santo Antônio de Goiás, GO, Brazil
}

\section{A R T I C L E I N F O}

\section{Keywords:}

Certified reference material

Genetically modified organism

Quantitative polymerase chain reaction

Common bean

Phaseolus vulgaris

EMB-PV051-1 event

\begin{abstract}
A B S T R A C T
The geminivirus-resistant common bean, Embrapa 5.1, was the first commercial genetically modified (GM) event developed in Latin America by the Brazilian Agricultural Research Corp.. Therein novel standard reference plasmids were constructed for species-specific (pLEC) and event-specific (pFGM) qualitative and quantitative detection of Embrapa 5.1 GM common bean. To establish these plasmids as certified reference materials (CRM) for Embrapa 5.1 GM common bean, two DNA extraction protocols, simplex and duplex qPCR using two different operators (experimenters) were tested. The efficiency values ranged from $92 \%$ to $110 \%$ for the simplex and duplex reactions considering both operators. The limit of detection was enough to detect at least $0.1 \%$ GM content. These plasmids are suitable to be used as CRM for Embrapa $5.1 \mathrm{GM}$ common bean. They will be useful for survey of food labels for compliance with legislation about GMO content in Brazil and in other countries where GM common bean is not yet approved for commercialization.
\end{abstract}

\section{Introduction}

Common bean (Phaseolus vulgaris L.) is a source of high quality proteins in the human diet worldwide (Mendoza-Sanchez et al., 2016; Parreira et al., 2016). It is an important staple food especially in Africa and Latin America (Carvalho et al., 2015; Schmutz et al., 2014). Brazil is among the world's leading producers and consumers of common beans (Faostat, 2016; Souza et al., 2018). In 2016, Brazilian production was 2.25 million metric tons of common bean on 1.56 million ha (Faostat, 2016; Souza et al., 2018). Embrapa 5.1 (EMB-PV051-1 event) genetically modified (GM) common bean was the first commercial GM plant developed in Latin America by the Brazilian Agricultural Research Corp. (Embrapa, Brasília, Brazil) to confer resistance to geminivirus (Aragao \& Faria, 2009). This event was approved for commercial release in Brazil by the Brazilian Biosafety Committee (http://ctnbio. mcti.gov.br, process 01200.005161-2010-86). Detailed molecular characterization of this event was described and agronomic performance and yield stability of GM lines were recently evaluated (Aragao, Nogueira, Tinoco, \& Faria, 2013; Souza et al., 2018).
Many countries established legislation for genetically modified organism (GMO) labelling of grains, feed and foodstuffs to provide consumer information. Generally labelling is mandatory if GMO content exceeds a certain threshold level (Gonzalez-Morales et al., 2015; Kamle \& Ali, 2013; Lin \& Pan, 2016). European Union (EC 1829/2003) and Russia established food labelling above 0.9\% GMO, Australia, Brazil, New Zealand, Saudi Arabia and Israel 1\%, Chile 2\% and Korea 3\%. Philippines, Indonesia, Taiwan and Japan introduced labelling above 5\% GMO. Country specific GMO labelling legislation was compiled previously (Kamle \& Ali, 2013). Since 2003 Brazilian legislation requires food and feed labelling above 1\% GMO (Brazil, 2003).

The quantitative real-time polymerase chain reaction (qPCR) has been the main tool for compliance with GM food labelling legislation (Lin \& Pan 2016, 2016; Meng, Liu, Wang, Zhang, \& Yang, 2012). Certified reference materials (CRM) are used in qPCR to determine the amount of GMO content in analyzed samples (Caprioara-Buda et al., 2012; Chaouachi, Ben Hafsa, Nabi, Zellama, \& Said, 2014; Charels et al., 2007), however there is a lack of certified material for some GMO (Holst-Jensen et al., 2012). CRM commonly used for GMO analysis are

\footnotetext{
* Corresponding author.

E-mail address: ana.arisi@ufsc.br (A.C.M. Arisi).
} 
dried powders, either genomic DNA (gDNA) or plasmid DNA (pDNA) (Caprioara-Buda et al., 2012). Dried powder CRM are mixtures of GM and non-GM seed powders gravimetrically determined, gDNA calibrators are extracted from leaves of a single GM plant and pDNA calibrators are recombinant plasmids containing an event-specific sequence and an endogenous reference gene sequence (Ballari, Martin, \& Gowda, 2013; Meng et al., 2012). These pDNA calibrators were single-target or multiple-target, some pDNA are commercially available as CRM (Table S1).

Dried powder CRM are produced based on weight equivalents and the GMO quantitation must be based on genome equivalents (Chaouachi et al., 2014), so there is no exact relationship between number of DNA molecules and weight (Taverniers, Van Bockstaele, \& De Loose, 2004). pDNA calibrators have some advantages compared to gDNA: they are easier to construct; can be produced at lower cost; they are stable frozen or lyophilized and can be stored for a long period of time; they are well-defined and have a fully characterized sequence (Burns et al., 2006; Caprioara-Buda et al., 2012; Wang et al., 2011). Plasmid calibrators have been considered adequate CRM because of their convenience and lower cost (Lievens et al., 2010; Meng et al., 2012).

A dual-target plasmid calibrant pcEM51 was previously developed for construct-specific (OLA assay) and endogenous reference (FEI assay) quantitation of Embrapa 5.1 GM common bean, but simplex qPCR using this plasmid as a DNA template showed low efficiency values and duplex qPCR was inhibited (Brod, Dinon, Kolling, Faria, \& Arisi, 2013). In recent work, a new and more suitable species-specific qPCR assay targeting the lectin gene was established (LEC assay) as an endogenous reference for the common bean (Venturelli et al., 2014) and an eventspecific qPCR assay was developed (FGM assay) for GM common bean Embrapa 5.1 detection (Treml, Venturelli, Brod, Faria, \& Arisi, 2014). FGM and LEC assays are able to detect and quantify the Embrapa 5.1 event to meet legislative requirements. In this work, two single-target plasmids were developed, the pLEC, targeting the lectin gene, the new endogenous reference and the pFGM, targeting the junction fragment of inserted transgene DNA and flanking DNA sequences of the host plant genome, the event-specific sequence. These new plasmids were tested using simplex and duplex $\mathrm{qPCR}$ to be CRM for Embrapa $5.1 \mathrm{GM}$ common bean quantitation.

\section{Material and methods}

\subsection{Plant material}

Seeds of Embrapa 5.1 (EMB-PV051-1 event) GM common bean ( $P$. vulgaris L.) derived from the Pérola cultivar and its non-GM cultivar were provided by Embrapa Arroz e Feijão (Santo Antônio de Goiás, Goiás State, Brazil). Soybean seeds (negative control) were purchased from a local market. They were grown in a controlled environmental growth chamber $\left(12 \mathrm{~h} \mathrm{dark} /\right.$ light at $150 \mu \mathrm{mol} / \mathrm{m}^{2} / \mathrm{s}$ and $25^{\circ} \mathrm{C}$ ) (Venturelli et al., 2014), the leaves were collected 11 days after seeding and stored a maximum of 30 days at $-80{ }^{\circ} \mathrm{C}$ until DNA extraction.

\subsection{DNA extraction}

Genomic DNA was extracted and purified from frozen leaf material using the DNeasy plant minikit (Qiagen, Hilde, Germany) according to the manufacturer's manual (named Protocol A). The plasmids were extracted using two protocols: PureYield plasmid miniprep system (Promega, Madison, WI, USA) according to the manufacturer's recommendation and a phenol-based protocol (Birnboim \& Doly, 1979), named protocols B and C, respectively. Total DNA quantitation was evaluated on a Thermo Scientific NanoDrop 2000 spectrophotometer (Wilmington, DE, USA).

\subsection{Primers and probes}

For pFGM plasmid construction, primer pair Bean2F/Vector2R were designed using Primer Express 3.0 software (Applied Biosystems, Foster, CA, USA) on the basis of Embrapa 5.1 GM common bean DNA sequence provided by EMBRAPA (Table S2). BeanF/VerctorR primers and the FGM probe (FGM assay) and PvLECF/PvLECR primers and PvLEC probe (LEC assay) were designed previously for event-specific quantitation of Embrapa 5.1 GM common bean, named FGM assay (Treml et al., 2014), and species-specific quantitation of common bean, named LEC assay (Venturelli et al., 2014). Primers were from Integrated DNA Technologies (Coralville, IA, USA) and probes were from Life Technologies (Carlsbad, CA, USA).

\subsection{Construction of pFGM and pLEC plasmids}

The primer pair Bean2F/VectorR was used to amplify a fragment of genomic DNA extracted from GM common bean targeting the junction sequence $(290 \mathrm{bp}$ ) between the common bean genomic DNA and the inserted DNA of Embrapa 5.1 GM. The reference fragment for the species-specific sequence ( $117 \mathrm{bp}$ ) was amplified using thePvLECF/PvLECR primer pair from non-GM common bean genomic DNA.

Introduction of amplified fragments into the pGEM-T Easy Vector (Promega) were made as previously described (Brod et al., 2013). Briefly, the pFGM and pLEC plasmids (Fig. 1) were both incubated with PagI (BspHI) restriction enzyme (Thermo Scientific), resulting in the linearization of the plasmids and releasing a non-target fragment of $1008 \mathrm{bp}$. The pLEC plasmid was also linearized with SalI restriction enzyme (Promega).

Linearized plasmids were purified using Wizard SV Gel and PCR Clean-Up System (Promega). Briefly, after electrophoresis to separate
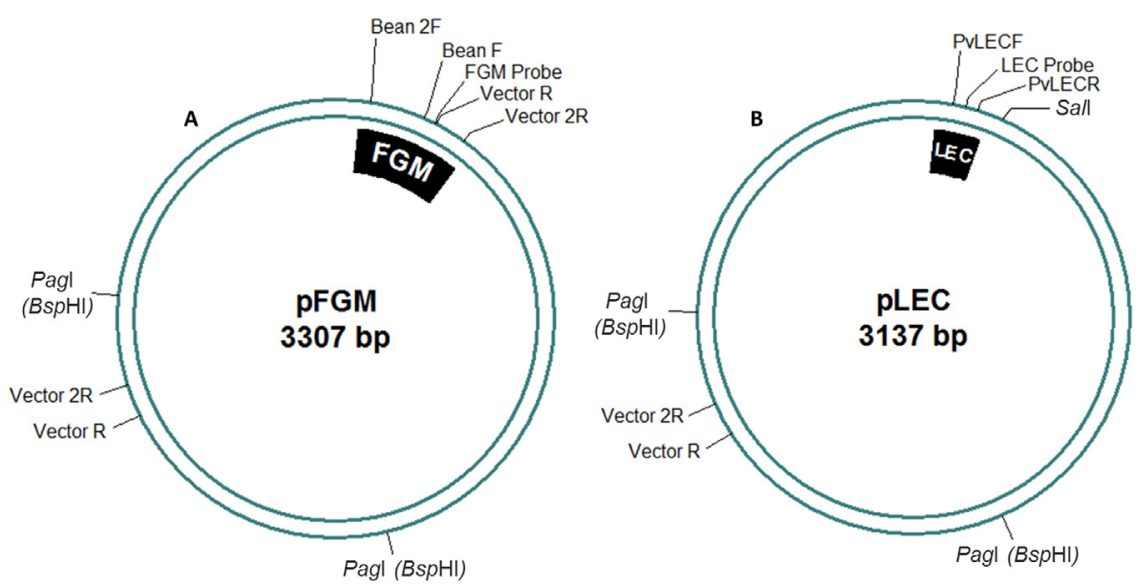

Fig. 1. Schematic diagram of constructed plasmids (A) pFGM, plasmid containing GM common bean junction fragment of inserted transgene DNA and flanking plant DNA sequence, insertion is labeled as FGM, and (B) pLEC, plasmid containing common bean lectin gene fragment, insertion is labeled as LEC. Restriction sites, primers and probes are marked. 
DNA fragments, the DNA band was excised from gel and dissolved with membrane binding solution. DNA was isolated using a DNA-binding minicolumn and microcentrifugation (Minispin, Eppendorf, Hamburg, Germany). DNA was eluted in ultrapure nuclease-free water (Promega). DNA concentration was quantified using the spectrophotometer.

\subsection{Preparation of plasmid (pDNA) and genomic DNA (gDNA) standard curves}

gDNA isolated from leaves of Embrapa 5.1 GM common bean was diluted in ultrapure water to $60.2 \mathrm{ng} / \mu \mathrm{L}$, it was 10 -fold serially diluted to obtain standard curves (Dinon et al., 2011). A mass of $60.2 \mathrm{ng}$ corresponds to $10^{9}$ gDNA copies based on the $P$. vulgaris genome size (549.6 Mbp) (Vlasova et al., 2016). Purified target fragments, pFGM fragment (Fig. 1A) cleaved using PagI (2299 bp), pLEC fragment (Fig. 1B) cleaved using PagI (2129 bp) or SalI (3137 bp), were diluted in water to obtain $2.52,3.44$ and $2.34 \mathrm{ng} / \mu \mathrm{L}$, respectively, which represent $10^{9} \mathrm{pDNA}$ copies/ $\mu \mathrm{L}$. The copy number was calculated using the equation $m=n \times 660 \times 1 / 6.023 \times 10^{23}$, where $n$ is the $1 \mathrm{C}$ value of 549.6 Mbp for gDNA or the plasmid length (bp) for pDNA. Amplification efficiency values were calculated using the equation $E(\%)=\left(10^{(-1 / s)}-1\right) \times 100$, where $E$ is the efficiency and $s$ is the slope obtained from the standard curve (Treml et al., 2014).

\subsection{Quantitative real-time PCR ( $q P C R$ )}

All qPCR were carried out in triplicate, in three distinct runs by two operators (experimenters), using an ABI PRISM 7500 detection system (Applied Biosystems, Foster, CA, USA) using TaqMan FGM and LEC probes (Life Technologies) (Treml et al., 2014; Venturelli et al., 2014). For duplex qPCR, BeanF/VectorR primer pair concentration was 400 $\mathrm{nmol} / \mathrm{L}$. Soybean DNA (10 ng) was used as a negative control sample in all qPCR plates.

\subsection{Statistical analysis}

Statistical analysis were done for qPCR efficiency values from standard curves obtained by two operators (experimenters), probability $(p)$ was calculated at $95 \%$ confidence level, using Tukey test post-hoc analysis after one-way ANOVA.

\section{Results and discussion}

Hydrolysis probe qPCR assays were developed to quantify Embrapa 5.1 (EMB-PV051-1 event) GM common bean, named the FGM assay (Treml et al., 2014), and to quantify common bean species endogenous reference, named the LEC assay (Venturelli et al., 2014). Since CRM for event-specific quantitation of GM common bean were not available, two single-target plasmids were developed: pFGM containing the eventspecific fragment and pLEC containing a fragment of Phaseolus vulgaris lectin gene, the species-specific sequence.

These new plasmids pLEC and pFGM (Fig. 1) were more applicable as CRM than the previously standard reference plasmid pcEM51 (Brod et al., 2013), which contains targets of the OLA and FEI assays. OLA and FEI assays could detect DNA quantitatively according to Brazilian GMO labelling requirements, though the efficiency values were below the recommended values for qPCR assays and duplex reactions were not possible. According to the European Network GMO Laboratories (ENGL), the efficiency values of a reliable GMO method must range from $90 \%$ to $110 \%$ (Engl, 2015). Moreover a construct-specific assay is suitable for screening but it cannot identify a specific GM event because the same construct can be present in more than one GM event. An event-specific assay represents the legal basis in the authorization of a GMO event for commercial use as food/feed (Holst-Jensen et al., 2012). Beyond that, the endogenous reference FEI assay (Dinon et al., 2012) showed greater heterogeneity among cultivars than the LEC assay
(Venturelli et al., 2014).

\subsection{Construction of PFGM and PLEC calibrators}

The presence of target fragments inserted in both pFGM and pLEC plasmids were confirmed using PCR and sequencing (Fig. S1). For pLEC, there is a plus of $7 \mathrm{bp}$ between the probe and reverse primer region, so the lectin fragment amplified from Pérola cultivar DNA has $117 \mathrm{bp}$ instead of the expected $110 \mathrm{bp}$ from alignment to the lectin gene available (GenBank accession J01261.1) (Schmutz et al., 2014) used for primers and probe design (Venturelli et al., 2014). This fragment was cloned and sequenced, the lectin gene sequence used for primer and probe design was different from the lectin gene sequence of the Pérola variety used for pLEC plasmid construction.

During plasmid preparation, bacterial genomic DNA may cause contamination. This potential genomic DNA contamination can affect qPCR efficiency values for calibration curves when undigested plasmid DNA is used as a calibrator. Also, plasmid linearization avoids reduced PCR efficiency caused by undigested plasmid DNA (Kim et al., 2015). This reduced efficiency could be caused by supercoiled pDNA, as reported previously (Caprioara-Buda et al., 2012).

For linearization, both pFGM and pLEC plasmids were digested with PagI, releasing a fragment of 1008 bp from both plasmids. This region was excluded from plasmids because they were annealing regions for Vector R and Vector 2R primers (Fig. 1), which could cause competition and/or no specific amplification in QPCR assays. The purified target fragments contained $2299 \mathrm{bp}$ from pFGM (Fig. 1A) and $2129 \mathrm{bp}$ from pLEC (Fig. 1B). The pLEC was also linearized with the SalI restriction enzyme, this linearized plasmid contained $3137 \mathrm{bp}$. These linearized plasmids were used as the template pDNA for FGM and LEC qPCR assays.

\section{2. $q P C R$ parameters}

To test the viability of these plasmids as standard references and calibrators for qPCR, two operators (experimenters) carried out all reactions and standard curves were compared (Fig. 2). pDNA was extracted using two different protocols and qPCR parameters were compared to those obtained with gDNA (Table 1).

The mean efficiency values for the FGM assay using pDNA samples extracted with PureYield plasmid miniprep system (protocol B) and phenol (protocol C), for both operators were in the range $90-110 \%$. Using the same samples, the LEC assay showed mean efficiency values in this range for both operators (Table 1). Efficiency values were neither statistically different between two different pDNA extraction protocols, nor the two operators (Table S3).

FGM and LEC assays were also tested with gDNA to compare the efficiency values with those obtained for pDNA. The mean efficiency values with gDNA for both assays and both operators were in the same range (Table 1). The results of both operators were statistically evaluated and a significant difference was observed for the LEC assay (Table S3). These efficiency values were also compared with those obtained for pDNA and a significant difference was observed only for operator 2 when comparing gDNA and pDNA extracted with protocol C (Table S3). All the other efficiency values showed no differences among DNA samples.

In previous work, efficiency values for pDNA were $76 \%$ and $81 \%$ for endogenous reference FEI assay and construct-specific OLA assay, respectively (Brod et al., 2013). Comparing these efficiency values with those obtained in this work, an improvement in qPCR parameters were observed with the new plasmids. Also, mean efficiency values for pDNA and gDNA (Table 1) are in accordance with the ENGL guideline, in the range $90-110 \%$ (Engl, 2015). Efficiency values for other GMO assays using gDNA and pDNA range from $82 \%$ to $112 \%$ (Caprioara-Buda et al., 2012; Chaouachi et al., 2014; Lievens et al., 2010; Wang et al., 2011). Mean efficiency values were close to acceptable range of $90-110 \%$, 

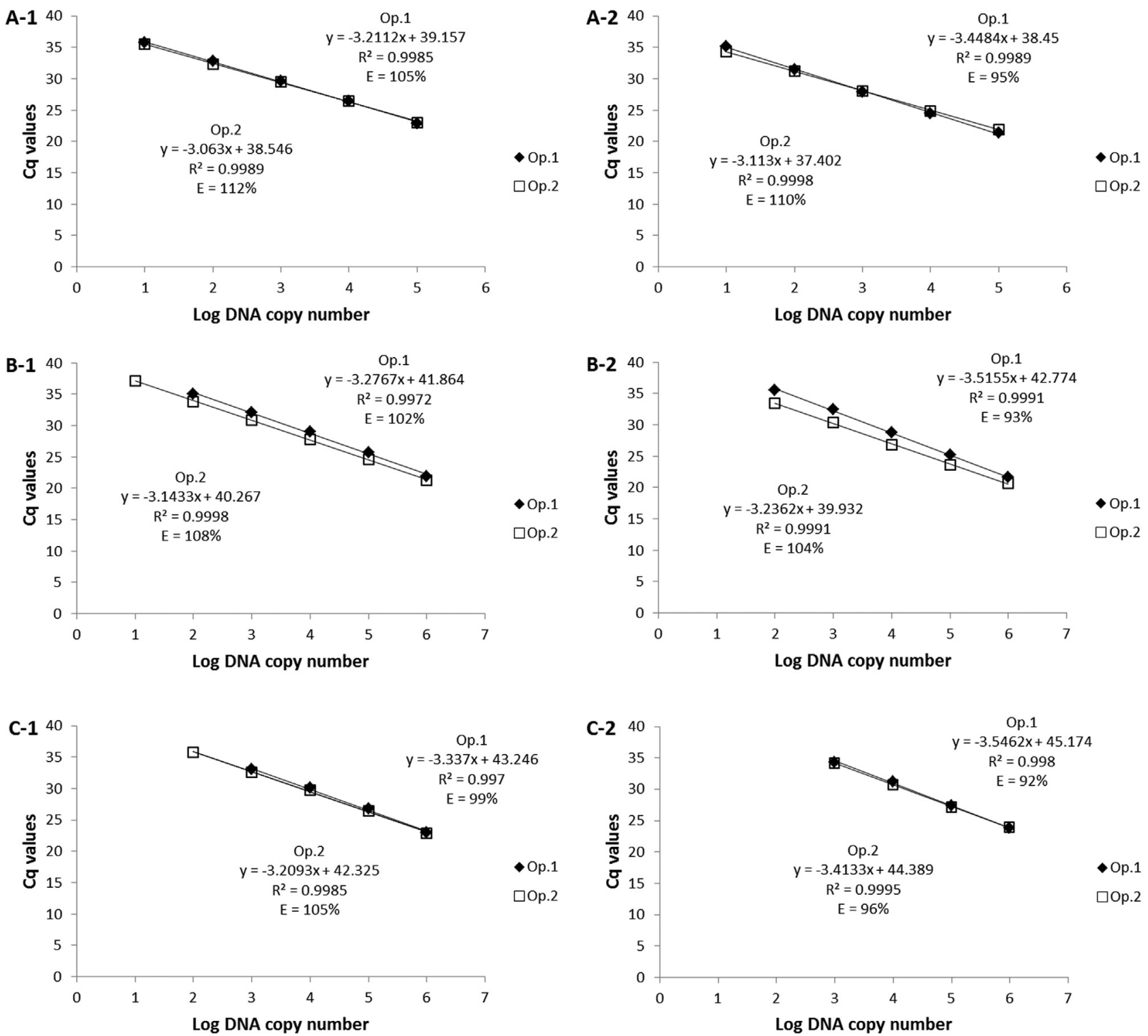

Fig. 2. Standard curves for FGM and LEC assays for three different days $(n=9)$ with different DNA samples and two operators (Op). (A) gDNA, (B) pDNA extracted with PureYield plasmid miniprep system, (C) pDNA extracted with phenol method, (1) FGM assay, (2) LEC assay.

which qualifies the proposed pDNA calibrators. Furthermore statistically significant differences were also reported for efficiency values by other authors that compared pDNA and gDNA calibrators for GMO quantitation using qPCR (Caprioara-Buda et al., 2012). The $\mathrm{R}^{2}$ values of qPCR standard curves were $>0.99$ for both assays and both operators with all DNA samples. These results are also in agreement with ENGL guidelines, which recommends $\mathrm{R}^{2}$ values $>0.98$ (Engl, 2015).

Accuracy was evaluated as the bias (\%) of the experimental mean value from the theoretical value (true DNA copy number) for each DNA sample (Tables 2 and 3). According to ENGL, bias values shall be within $\pm 25 \%$ (Engl, 2015). Considering both operators, bias values ranged from $-17.4 \%$ to $21.2 \%$ for the FGM assay (Table 2), except for one (26.7), and from $-17.3 \%$ to $19.3 \%$ for the LEC assay (Table 3 ). These results were within the acceptance criteria and they were similar to other reports (Chaouachi et al., 2014; Lee, Kim, \& Yi, 2009; Wang et al., 2011).

\subsection{Limit of detection and limit of quantitation}

The limit of detection (LOD) is the lowest amount of analyte in a sample that can be reliably detected and it should be detected at least 95\% of the time (Engl, 2015). The limit of quantitation (LOQ) is the lowest amount or concentration of analyte in a sample, which can be reliably quantified with an acceptable level of precision and trueness (Engl, 2015). LOD and LOQ were determined for gDNA and pDNA extracted with different protocols and soybean DNA as a negative control. LOD and LOQ were estimated in 18 PCR replicates. LOQ was estimated as the last dilution level where the relative standard deviation of the measurements was below 25\% (Table 4).

The LOD value of $10^{1}$ for gDNA (Table 4) was also obtained in previous work about FGM and LEC assays development (Treml et al., 2014; Venturelli et al., 2014). Furthermore, this value is lower than those obtained for previous OLA and FEI assays, LOD of $10^{2}$ gDNA copy number (Brod et al., 2013). Based on this LOD of $10^{1}$ copy number of gDNA and common bean genome length, the FGM and LEC assays would be sufficient to detect GM common bean DNA representing $0.01-100 \%$ of $50 \mathrm{ng}$ of DNA sample, similar to other reports (Wang et al., 2011).

Considering pDNA, the lowest amount of DNA that was reliably detected in both FGM and LEC assays was $10^{2}$ and $10^{3}$ for pDNA 
Table 1

Efficiency values for duplex, FGM and LEC assay in three independent runs with genomic DNA and plasmid DNA extracted with different DNA extraction protocols and two operators (Op.).

\begin{tabular}{|c|c|c|c|c|c|c|c|c|}
\hline \multicolumn{9}{|c|}{ Efficiency (\%) } \\
\hline & \multicolumn{2}{|l|}{$\mathrm{gDNA}^{\mathrm{a}}$} & \multicolumn{2}{|l|}{$\mathrm{pDNA}^{\mathrm{b}}$} & \multicolumn{2}{|c|}{ pDNA $^{c}$} & \multicolumn{2}{|c|}{$\begin{array}{l}\text { Duplex }\left(\mathrm{pFGM}^{\mathrm{b}}+\right. \\
\left.\text { pLEC }^{\mathrm{b}}\right)\end{array}$} \\
\hline & Op. 1 & Op. 2 & Op. 1 & Op. 2 & Op. 1 & Op. 2 & Op. 1 & Op. 2 \\
\hline \multicolumn{9}{|l|}{ FGM } \\
\hline Run 1 & 104 & 109 & 105 & 107 & 96 & 105 & 104 & 107 \\
\hline Run 2 & 104 & 113 & 101 & 115 & 99 & 108 & 108 & 110 \\
\hline Run 3 & 106 & 114 & 100 & 103 & 103 & 102 & 104 & 112 \\
\hline Mean & 105 & 112 & 102 & 108 & 99 & 105 & 105 & 110 \\
\hline \multicolumn{9}{|l|}{ LEC } \\
\hline Run 1 & 92 & 106 & 97 & 103 & 95 & 94 & 91 & 99 \\
\hline Run 2 & 98 & 110 & 87 & 104 & 92 & 94 & 106 & 96 \\
\hline Run 3 & 95 & 113 & 94 & 104 & 88 & 101 & 105 & 96 \\
\hline Mean & 95 & 110 & 93 & 104 & 92 & 96 & 101 & 97 \\
\hline
\end{tabular}

a gDNA extracted with DNeasy plant mini kit.

b pDNA extracted with PureYield plasmid miniprep system.

c pDNA extracted with phenol protocol.

extracted with protocols B and C, respectively (Table 4). These LOD values would be sufficient to detect $0.1 \%$ and $1 \%$ of Embrapa 5.1 common bean DNA using $50 \mathrm{ng}$ of template DNA. The amount of DNA reliable detected using DNA extraction protocol B was sufficient to detect $0.1 \%$ GM content, which makes it suitable for quantitative analysis of GM samples even with low GMO content. Other publications on plasmid calibrator development reported LOD around 10 copy number (Ballari et al., 2013; Chaouachi et al., 2014; Meng et al., 2012; Wang et al., 2011).

\subsection{Duplex $q P C R$}

Duplex PCR is advantageous since it can accelerate testing protocols by reducing sample loads, and conserving time and resources. A direct relation between \%GMO and $\mathrm{qPCR}$ results can be established using duplex reaction, it reduces the test variability and permits accurate data interpretation (Chaouachi et al., 2014). In this way, pFGM and pLEC calibrators were tested with duplex FGM and LEC qPCR to evaluate the viability of this method for quantitation of GM common bean. The duplex qPCR were done by both operators with pDNA extracted using protocol B (Fig. 3).

With operator 1, the efficiency values for the FGM assay ranged from $104 \%$ to $108 \%$, with a mean efficiency of $105 \%$ (Table 1 ). For the LEC assay, the efficiency values ranged from $91 \%$ to $106 \%$, with a mean efficiency of $101 \%$ (Table 1 ). When the reactions were done with operator 2 , the efficiency values ranged from $107 \%$ to $112 \%$ for the FGM assay and the mean efficiency was $110 \%$ (Table 1). For the LEC assay, the efficiency values ranged from $96 \%$ to $99 \%$, with a mean efficiency of $97 \%$ (Table 1 ). The $\mathrm{R}^{2}$ values were $>0.98$ for both assays with both operators. These results show that the efficiency values and the linearity obtained using simplex and duplex systems were acceptable, indicating no losses and no interferences in quantitation using the duplex system.

With regard to LOD and LOQ values, they were the same as obtained with simplex reactions, being $10^{2}$ DNA copy number for both assays (Table 4), confirming the duplex system is as good as simplex FGM and LEC assays for GM common bean Embrapa 5.1 event quantitation.

Many duplex assays were validated in the past few years for GMO detection and quantitation, as screening methods for detection of GMO in food and feed (Huber et al., 2013; Waiblinger, Ernst, Anderson, \& Pietsch, 2008); quantitation of GM soybean (Samson, Gulli, \& Marmiroli, 2010) and GM maize (Lee et al., 2009). Plasmid calibrators

Table 2

Comparison of repeatability of FGM assay for two operators and different DNA samples.

\begin{tabular}{|c|c|c|c|c|c|c|c|c|c|c|c|c|}
\hline \multirow{3}{*}{ True copy number } & \multicolumn{6}{|c|}{ Operator 1} & \multicolumn{6}{|c|}{ Operator 2} \\
\hline & \multirow{2}{*}{$\begin{array}{l}\text { Run } 1 \\
\mathrm{Cq}\end{array}$} & \multirow{2}{*}{$\begin{array}{l}\text { Run } 2 \\
\mathrm{Cq}\end{array}$} & \multirow{2}{*}{$\begin{array}{l}\text { Run } 3 \\
\mathrm{Cq}\end{array}$} & \multirow[b]{2}{*}{ SD } & \multirow[t]{2}{*}{ Experimental copy number } & \multirow[b]{2}{*}{ Bias (\%) } & \multirow{2}{*}{$\begin{array}{l}\text { Run } 1 \\
\mathrm{Cq}\end{array}$} & \multirow{2}{*}{$\begin{array}{l}\text { Run } 2 \\
\mathrm{Cq}\end{array}$} & \multirow{2}{*}{$\begin{array}{l}\text { Run } 3 \\
\mathrm{Cq}\end{array}$} & \multirow{2}{*}{\multicolumn{2}{|c|}{ Experimental copy number }} & \multirow[b]{2}{*}{ Bias $(\%$} \\
\hline & & & & & & & & & & & & \\
\hline \multicolumn{13}{|l|}{$\mathrm{gDNA}^{\mathrm{a}}$} \\
\hline 100000 & 22.7 & 23.0 & 22.9 & 0.15 & 117771 & 17.8 & 22.3 & 23.2 & 23.6 & 0.61 & 114438 & 14.4 \\
\hline 10000 & 26.3 & 26.5 & 26.6 & 0.27 & 8875 & -11.3 & 25.8 & 26.5 & 27.2 & 0.63 & 8640 & -13.6 \\
\hline 1000 & 29.4 & 29.9 & 29.7 & 0.28 & 900 & -10.0 & 28.7 & 29.7 & 30.0 & 0.61 & 911 & -8.9 \\
\hline 100 & 32.8 & 32.9 & 32.9 & 0.21 & 92 & -8.0 & 31.5 & 32.4 & 33.0 & 0.67 & 111 & 10.9 \\
\hline 10 & 35.6 & 35.9 & 35.7 & 0.63 & 12 & 15.7 & 35.1 & 35.5 & 35.8 & 0.50 & 10 & 1.6 \\
\hline \multicolumn{13}{|l|}{$\mathrm{pFGM}^{\mathrm{b}}$} \\
\hline 1000000 & 21.7 & 22.1 & 21.8 & 0.25 & 1266819 & 26.7 & 22.0 & 21.3 & 20.6 & 0.67 & 1060960 & 6.1 \\
\hline 100000 & 25.4 & 25.8 & 25.9 & 0.31 & 85926 & -14.1 & 25.7 & 24.2 & 23.8 & 0.96 & 98437 & -1.6 \\
\hline 10000 & 28.6 & 29.4 & 29.1 & 0.40 & 8260 & -17.4 & 28.8 & 27.4 & 27.1 & 0.86 & 9284 & -7.2 \\
\hline 1000 & 32.0 & 32.2 & 32.1 & 0.16 & 962 & -3.8 & 32.0 & 30.4 & 30.1 & 0.89 & 986 & -1.4 \\
\hline 100 & 34.5 & 35.3 & 35.4 & 0.57 & 119 & 19.0 & 35.2 & 33.3 & 33.1 & 1.03 & 110 & 10.4 \\
\hline 10 & - & - & - & - & - & - & 37.9 & 36.4 & 37.2 & 0.97 & 10 & -0.2 \\
\hline \multicolumn{13}{|l|}{$\mathrm{pFGM}^{\mathrm{c}}$} \\
\hline 1000000 & 22.0 & 23.5 & 23.5 & 0.74 & 1176361 & 17.6 & 22.7 & 22.8 & 23.0 & 0.34 & 1135355 & 13.5 \\
\hline 100000 & 26.0 & 27.2 & 27.1 & 0.56 & 87340 & -12.7 & 26.4 & 26.3 & 26.7 & 0.24 & 87465 & -12.5 \\
\hline 10000 & 29.3 & 30.5 & 30.4 & 0.60 & 8943 & -10.6 & 29.5 & 29.5 & 30.1 & 0.37 & 8942 & -10.6 \\
\hline 1000 & 32.3 & 33.5 & 33.2 & 0.59 & 1181 & 18.1 & 32.6 & 32.3 & 33.0 & 0.33 & 1128 & 12.8 \\
\hline 100 & - & - & - & - & - & - & 35.6 & 35.5 & 36.3 & 0.58 & 121 & 21.2 \\
\hline \multicolumn{13}{|c|}{ Duplex $\left(\mathrm{pFGM}^{\mathrm{b}}+\mathrm{pLEC}^{\mathrm{b}}\right)$} \\
\hline 1000000 & 21.2 & 22.1 & 21.5 & 0.48 & 1376171 & 37.6 & 21.4 & 21.9 & 21.8 & 0.34 & 1156273 & 15.6 \\
\hline 100000 & 25.3 & 26.1 & 25.5 & 0.51 & 73748 & -26.3 & 25.0 & 25.5 & 25.0 & 0.27 & 91274 & -8.7 \\
\hline 10000 & 28.5 & 29.0 & 28.6 & 0.34 & 8085 & -19.2 & 28.1 & 28.8 & 28.2 & 0.40 & 8619 & -13.8 \\
\hline 1000 & 31.2 & 31.8 & 31.5 & 0.32 & 1084 & 8.4 & 31.0 & 31.7 & 31.3 & 0.35 & 1006 & 0.6 \\
\hline 100 & 34.5 & 34.9 & 34.6 & 0.52 & 112 & 12.3 & 34.4 & 34.6 & 34.0 & 0.47 & 111 & 10.5 \\
\hline 10 & - & - & - & - & - & - & 37.3 & 37.6 & 37.2 & 0.46 & 12 & 19.2 \\
\hline
\end{tabular}

a gDNA extracted with DNeasy plant mini kit.

b pDNA extracted with PureYield plasmid miniprep system.

c pDNA extracted with phenol method. 
Table 3

Comparison of repeatability of LEC assay for two operators and different DNA samples.

\begin{tabular}{|c|c|c|c|c|c|c|c|c|c|c|c|c|}
\hline \multirow{3}{*}{ True copy number } & \multicolumn{6}{|c|}{ Operator 1} & \multicolumn{6}{|c|}{ Operator 2} \\
\hline & \multirow{2}{*}{$\begin{array}{l}\text { Run } 1 \\
\mathrm{Cq}\end{array}$} & \multirow{2}{*}{$\begin{array}{l}\text { Run } 2 \\
\text { Cq }\end{array}$} & \multicolumn{2}{|l|}{ Run 3} & \multirow[t]{2}{*}{ Experimental copy number } & \multirow[b]{2}{*}{ Bias (\%) } & \multirow{2}{*}{$\begin{array}{l}\text { Run } 1 \\
\text { Cq }\end{array}$} & \multirow{2}{*}{$\begin{array}{l}\text { Run } 2 \\
\text { Cq }\end{array}$} & \multicolumn{2}{|l|}{ Run 3} & \multirow[t]{2}{*}{ Experimental copy number } & \multirow[b]{2}{*}{ Bias (\%) } \\
\hline & & & $\mathrm{Cq}$ & SD & & & & & $\mathrm{Cq}$ & SD & & \\
\hline \multicolumn{13}{|l|}{ gDNA $^{\mathrm{a}}$} \\
\hline 100000 & 22.0 & 21.6 & 20.7 & 0.56 & 87392 & -12.6 & 21.4 & 20.1 & 24.1 & 1.77 & 95373 & -4.6 \\
\hline 10000 & 24.9 & 24.6 & 24.0 & 0.42 & 11025 & 10.2 & 24.3 & 23.2 & 27.0 & 1.69 & 10988 & 9.9 \\
\hline 1000 & 28.5 & 28.0 & 27.4 & 0.48 & 1096 & 9.6 & 27.5 & 26.6 & 30.2 & 1.64 & 978 & -2.2 \\
\hline 100 & 31.7 & 31.6 & 31.0 & 0.40 & 109 & 9.3 & 30.8 & 29.6 & 33.3 & 1.66 & 97 & -3.1 \\
\hline \multicolumn{13}{|l|}{$\mathrm{pLEC}^{\mathrm{b}}$} \\
\hline 1000000 & 21.6 & 20.5 & 22.7 & 0.93 & 1066224 & 6.6 & 20.4 & 21.0 & 20.5 & 0.26 & 921532 & -7.8 \\
\hline 100000 & 25.1 & 23.9 & 26.3 & 1.07 & 106636 & 6.6 & 23.7 & 23.5 & 23.8 & 0.15 & 108141 & 8.1 \\
\hline 10000 & 29.0 & 27.5 & 29.7 & 1.01 & 9923 & -0.8 & 26.5 & 26.6 & 27.3 & 0.39 & 11688 & 16.9 \\
\hline 1000 & 32.7 & 31.2 & 33.4 & 1.05 & 888 & -11.2 & 30.2 & 30.7 & 30.2 & 0.31 & 895 & -10.5 \\
\hline \multicolumn{13}{|l|}{$\mathrm{pLEC}^{\mathrm{c}}$} \\
\hline 1000000 & 23.2 & 24.4 & 23.8 & 0.50 & 1099257 & 9.9 & 23.3 & 24.0 & 24.7 & 0.61 & 939742 & -6.0 \\
\hline 100000 & 26.8 & 28.2 & 27.2 & 0.66 & 103387 & 3.4 & 26.4 & 27.3 & 27.9 & 0.71 & 109135 & 9.1 \\
\hline 10000 & 30.4 & 31.5 & 31.9 & 1.19 & 8266 & -17.3 & 30.1 & 30.6 & 31.4 & 0.58 & 10208 & 2.1 \\
\hline 1000 & 33.6 & 35.1 & 34.4 & 0.85 & 1066 & 6.6 & 33.6 & 34.5 & 34.5 & 0.57 & 964 & -3.6 \\
\hline \multicolumn{13}{|c|}{ Duplex $\left(\mathrm{pFGM}^{\mathrm{b}}+\mathrm{pLEC}^{\mathrm{b}}\right)$} \\
\hline 1000000 & 20.8 & 22.3 & 20.4 & 0.87 & 1635535 & 63.6 & 20.2 & 19.8 & 20.3 & 0.26 & 1168165 & 16.8 \\
\hline 100000 & 25.4 & 27.6 & 25.9 & 1.16 & 48200 & -51.8 & 24.0 & 23.5 & 23.9 & 0.28 & 93789 & -6.2 \\
\hline 10000 & 28.3 & 29.2 & 27.5 & 0.76 & 11437 & 14.4 & 27.5 & 27.3 & 27.5 & 0.46 & 8154 & -18.5 \\
\hline 1000 & 31.8 & 32.5 & 30.8 & 0.79 & 1109 & 10.9 & 30.6 & 30.2 & 30.8 & 0.37 & 990 & -1.0 \\
\hline 100 & 35.4 & 35.8 & 34.0 & 0.97 & 108 & 8.0 & 33.8 & 33.5 & 33.9 & 0.33 & 114 & 13.7 \\
\hline
\end{tabular}

a gDNA extracted with DNeasy plant mini kit.

b pDNA extracted with PureYield plasmid miniprep system.

c pDNA extracted with phenol method.

Table 4

Limit of detection (LOD) and limit of quantitation (LOQ) in copy number for FGM and LEC assays.

\begin{tabular}{lccccc}
\hline & \multicolumn{2}{l}{ LOD (copy number) } & & \multicolumn{2}{l}{ LOQ (copy number) } \\
\cline { 2 - 3 } \cline { 5 - 6 } Template DNA & FGM assay & LEC assay & & FGM assay & LEC assay \\
\hline gDNA $^{\text {a }}$ & 10 & 10 & & 10 & 10 \\
pDNA $^{\mathrm{b}}$ & 100 & 100 & & 100 & 100 \\
pDNA $^{\mathrm{c}}$ & 1000 & 1000 & & 1000 & 1000 \\
Duplex $^{\mathrm{d}}$ & 100 & 100 & & 100 & 100 \\
\hline
\end{tabular}

a gDNA extracted with DNeasy plant mini kit.

b pDNA extracted with PureYield plasmid miniprep system.

c pDNA extracted with phenol method.

d Duplex (pFGM $\left.{ }^{\mathrm{b}}+\mathrm{pLEC}^{\mathrm{b}}\right)$.

were developed and tested using duplex qPCR for quantitation of canola (Chaouachi et al., 2014) and soybean (Zhang et al., 2008). Results obtained in this work corroborated those obtained previously for other

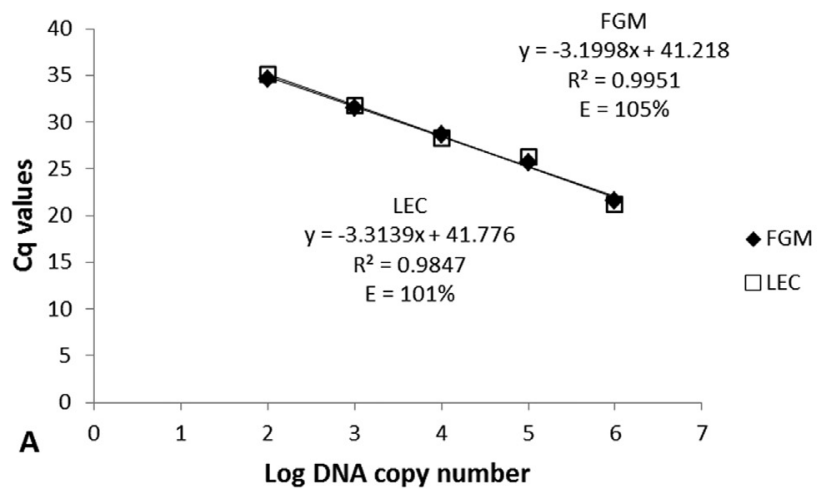

GMO event duplex qPCR assays. These two new plasmids showed stability and reliability through tests with two operators. In addition, the pFGM and the pLEC brought the improvements necessary to establish them as a standard reference.

\section{Conclusion}

These results indicated that pFGM and pLEC plasmids are suitable to be used as standard reference molecules as positive control and calibrators for the practical detection and quantitation of GM common bean Embrapa 5.1 using simplex or duplex qPCR to meet food labelling requirements.

\section{Acknowledgments}

We would like to thank Dr. Gustavo Klabunde from LFDGV UFSC for plasmid sequence services. The work was financially supported by the National Council for Scientific and Technological Development (CNPq)

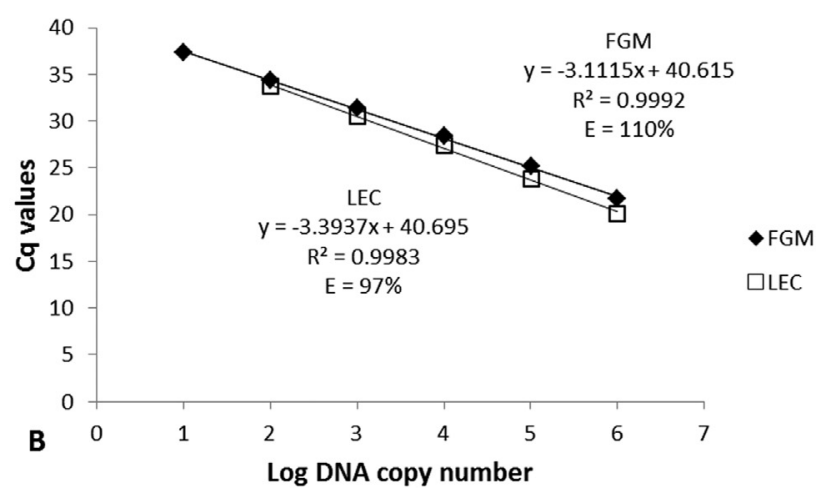

Fig. 3. Duplex standard curves for FGM and LEC assays for three different days $(n=9)$ with pDNA extracted with PureYield plasmid miniprep system and two operators. (A) Operator 1, (B) Operator 2. 
process 304666/2015-7, Ministry of Science and Technology, Brazil. GLV and KJS were recipients of Ph.D. and post-doctoral fellowships from the Coordination for the Improvement of Higher Education Personnel (CAPES), Ministry of Education, Brazil and ACMA is a recipient of a research fellowship (PQ2) from CNPq.

\section{Conflict of interest statement}

\section{We have no conflict of interest.}

\section{Appendix A. Supporting information}

Supplementary data associated with this article can be found in the online version at doi:10.1016/j.fbio.2018.10.007.

\section{References}

Aragao, F. J. L., \& Faria, J. C. (2009). First transgenic geminivirus-resistant plant in the field. Nature Biotechnology, 27(12), 1086-1088.

Aragao, F. J. L., Nogueira, E., Tinoco, M. L. P., \& Faria, J. C. (2013). Molecular characterization of the first commercial transgenic common bean immune to the bean golden mosaic virus. Journal of Biotechnology, 166(1-2), 42-50.

Ballari, R. V., Martin, A., \& Gowda, L. R. (2013). A calibrator plasmid for quantitative analysis of insect resistant maize (Yieldgard MON 810). Food Chemistry, 140(1-2), 382-389.

Birnboim, H. C., \& Doly, J. (1979). Rapid alkaline extraction procedure for screening recombinant plasmid DNA. Nucleic Aci Research, 7(6), 1513-1523.

Brazil (2003). Decree no. 4.680, April 24, Regulates the information access concerning foods and ingredients containing or produced from genetically modified organisms. D.O.U. Official Journal of Brazil, www.anvisa.gov.br/e-legis/ ed. (accessed December 2016).

Brod, F., Dinon, A., Kolling, D., Faria, J., \& Arisi, A. (2013). Development of plasmid DNA reference material for the quantification of genetically modified common bean Embrapa 5.1. Journal of Agricultural and Food Chemistry, 61(20), 4921-4926.

Burns, M., Corbisier, P., Wiseman, G., Valdivia, H., McDonald, P., Bowler, P., ... Harris, N. (2006). Comparison of plasmid and genomic DNA calibrants for the quantification of genetically modified ingredients. European Food Research and Technology, 224(2), 249-258.

Caprioara-Buda, M., Meyer, W., Jeynov, B., Corbisier, P., Trapmann, S., \& Emons, H. (2012). Evaluation of plasmid and genomic DNA calibrants used for the quantification of genetically modified organisms. Analytical and Bioanalytical Chemistry, 404(1), $29-42$.

Carvalho, J. L. V., Santos, J. D., Conte, C., Pacheco, S., Nogueira, E., Souza, T., ... Aragao, F. J. L. (2015). Comparative analysis of nutritional compositions of transgenic RNAimediated virus-resistant bean (event EMB-PV051-1) with its non-transgenic counterpart. Transgenic Research, 24(5), 813-819.

Chaouachi, M., Ben Hafsa, A., Nabi, N., Zellama, M. S., \& Said, K. (2014). A new dual plasmid calibrator for the quantification of the construct specific GM canola Oxy-235 with duplex real-time PCR. Food Chemistry, 145, 49-56.

Charels, D., Broeders, S., Corbisier, P., Trapmann, S., Schimmel, H., \& Emons, H. (2007). Toward metrological traceability for DNA fragment ratios in GM quantification. 3. Suitability of DNA calibrants studied with a MON 810 corn model. Journal of Agricultural and Food Chemistry, 55(9), 3268-3274.

Dinon, A. Z., Brod, F. C. A., Mello, C. S., Oliveira, E. M. M., Faria, J. C., \& Arisi, A. C. M. (2012). Primers and probes development for specific PCR detection of genetically modified common bean (Phaseolus vulgaris) Embrapa 5.1. Journal of Agricultural and Food Chemistry, 60(18), 4672-4677.

Dinon, A. Z., Prins, T. W., van Dijk, J. P., Arisi, A. C. M., Scholtens, I. M. J., \& Kok, E. J. (2011). Development and validation of real-time PCR screening methods for detection of cry1A.105 and cry2Ab2 genes in genetically modified organisms. Analytical and Bioanalytical Chemistry, 400(5), 1433-1442.

Engl (2015). Definition of Minimum Performance Requirements for Analytical Methods of GMO Testing. European Network of GMO Laboratories. 〈http://gmo-crl.jrc.ec. europa.eu/doc/MPR\%20Report\%20Application\%2020_10_2015.pdf $>$ Accessed December 2016.

Faostat (2016). Food and Agriculture Data, Food and Agriculture Organization of the United Nations, The Statistics Division of the FAO, Rome, Italy, 〈http://www.fao, org/faostat/en/\#data/QC> (acessed December 2016).
Gonzalez-Morales, S., Cruz-Requena, M., Rodriguez-Vidal, A., Aguilar-Gonzalez, C. N., Rebolloso-Padilla, O. N., \& Rodriguez-Herrera, R. (2015). Persistence of transgenic genes and proteins during soybean food processing. Food Bioscience, 11, 43-47.

Holst-Jensen, A., Bertheau, Y., de Loose, M., Grohmann, L., Hamels, S., Hougs, L., .. (2012). Detecting un-authorized genetically modified organisms (GMOs) and derived materials. Biotechnology Advances, 30(6), 1318-1335.

Huber, I., Block, A., Sebah, D., Debode, F., Morisset, D., Grohmann, L., ... Busch, U. (2013). Development and validation of duplex, triplex, and pentaplex real-time PCR screening assays for the detection of genetically modified organisms in food and feed. Journal of Agricultural and Food Chemistry, 61(43), 10293-10301.

Kamle, S., \& Ali, S. (2013). Genetically modified crops: Detection strategies and biosafety issues. Gene, 522(2), 123-132.

Kim, J.-H., Park, S.-B., Roh, H.-J., Woo, H.-B., Shin, M.-K., Moon, G. I., ... Kim, H.-Y. (2015). Event-specific qualitative and quantitative detection of three genetically modified papaya events using a single standard reference molecule. Food Control, 55, $127-132$.

Lee, S. H., Kim, S. J., \& Yi, B. Y. (2009). Simplex and duplex event-specific analytical methods for functional biotech maize. Journal of Agricultural and Food Chemistry, 57(16), 7178-7185.

Lievens, A., Bellocchi, G., De Bernardi, D., Moens, W., Savini, C., Mazzara, M., ... Van den Bulcke, M. (2010). Use of pJANUS (TM)-02-001 as a calibrator plasmid for Roundup ready soybean event GTS-40-3-2 detection: An interlaboratory trial assessment. Analytical and Bioanalytical Chemistry, 396(6), 2165-2173.

Lin, C.-H., \& Pan, T.-M. (2016). Perspectives on genetically modified crops and food detection. Journal of Food and Drug Analysis, 24(1), 1-8.

Mendoza-Sanchez, M., Guevara-Gonzalez, R. G., Castano-Tostado, E., Mercado-Silva, E. M., Acosta-Gallegos, J. A., Rocha-Guzman, N. E., \& Reynoso-Camacho, R. (2016). Effect of chemical stress on germination of cv dalia bean (Phaseolus vulgaris L.) as an alternative to increase antioxidant and nutraceutical compounds in sprouts. Food Chemistry, 212, 128-137.

Meng, Y. A., Liu, X., Wang, S., Zhang, D. B., \& Yang, L. T. (2012). Applicability of plasmid calibrant pTC1507 in quantification of TC1507 maize: An interlaboratory study. Journal of Agricultural and Food Chemistry, 60(1), 23-28.

Parreira, J. R., Bouraada, J., Fitzpatrick, M. A., Silvestre, S., da Silva, A. B., da Silva, J. M., .. Araujo, S. S. (2016). Differential proteomics reveals the hallmarks of seed development in common bean (Phaseolus vulgaris L.). Journal of Proteomics, 143, 188-198.

Samson, M. C., Gulli, M., \& Marmiroli, N. (2010). Quantitative detection method for Roundup Ready (R) soybean in food using duplex real-time PCR MGB chemistry. Journal of the Science of Food and Agriculture, 90(9), 1437-1444.

Schmutz, J., McClean, P. E., Mamidi, S., Wu, G. A., Cannon, S. B., Grimwood, J., ... Jackson, S. A. (2014). A reference genome for common bean and genome-wide analysis of dual domestications. Nature Genetics, 46(7), 707-713.

Souza, T., Faria, J. C., Aragao, F. J. L., Del Peloso, M. J., Faria, L. C., Wendland, A., .. Melo, L. C. (2018). Agronomic performance and yield stability of the RNA interference-based bean golden mosaic virus-resistant common bean. Crop Science, 58(2), 579-591.

Taverniers, I., Van Bockstaele, E., \& De Loose, M. (2004). Cloned plasmid DNA fragments as calibrators for controlling GMOs: Different real-time duplex quantitative PCR methods. Analytical and Bioanalytical Chemistry, 378(5), 1198-1207.

Treml, D., Venturelli, G. L., Brod, F. C. A., Faria, J. C., \& Arisi, A. C. M. (2014) Development of an event-specific hydrolysis probe quantitative real-time polymerase chain reaction assay for Embrapa 5.1 genetically modified common bean (Phaseolus vulgaris). Journal of Agricultural and Food Chemistry, 62(49), 11994-12000.

Venturelli, G. L., Brod, F. C. A., Rossi, G. B., Zimmermann, N. F., Oliveira, J. P., Faria, J. C., \& Arisi, A. C. M. (2014). A specific endogenous reference for genetically modified common bean (Phaseolus vulgaris L.) DNA quantification by real-time PCR targeting lectin gene. Molecular Biotechnology, 56(11), 1060-1068.

Vlasova, A., Capella-Gutierrez, S., Rendon-Anaya, M., Hernandez-Onate, M., Minoche, A., Erb, I., ... Guigo, R. (2016). Genome and transcriptome analysis of the Mesoamerican common bean and the role of gene duplications in establishing tissue and temporal specialization of genes. Genome Biology, 17, 32.

Waiblinger, H.-U., Ernst, B., Anderson, A., \& Pietsch, K. (2008). Validation and collaborative study of a P35S and T-nos duplex real-time PCR screening method to detect genetically modified organisms in food products. European Food Research and Technology, 226(5), 1221-1228.

Wang, X., Teng, D., Yang, Y., Tian, F., Guan, Q., \& Wang, J. (2011). Construction of a reference plasmid molecule containing eight targets for the detection of genetically modified crops. Applied Microbiology and Biotechnology, 90(2), 721-731.

Zhang, H. B., Yang, L. T., Guo, J. C., Li, X., Jiang, L. X., \& Zhang, D. B. (2008). Development of one novel multiple-target plasmid for duplex quantitative PCR analysis of Roundup Ready soybean. Journal of Agricultural and Food Chemistry, 56(14), 5514-5520. 